\title{
Experimental and modeling study of water defluoridation using waste granular brick in a continuous up-flow fixed bed
}

\author{
Ziad T. Abd Ali, Zainab Z. Ismail ${ }^{\dagger}$ \\ Department of Environmental Engineering, University of Baghdad, Baghdad, Iraq
}

\begin{abstract}
Contamination of surface and groundwater with excessive concentrations of fluoride is of significant health hazard. Adsorption of fluoride onto waste materials of no economic value could be a potential approach for the treatment of fluoride-bearing water. This experimental and modeling study was devoted to investigate the fluoride removal using unmodified waste granular brick (WGB) in a fixed bed running in continuous mode. Characterization of WGB was carried out by FT-IR, SEM, and EDX analysis. The batch mode experiments showed that they were affected by several parameters including contact time, initial $\mathrm{pH}$, and sorbent dosage. The best values of these parameters that provided maximum removal percent $(82 \%)$ with the initial concentration of $\mathrm{F}^{-1}$ ions $(10 \mathrm{mg} / \mathrm{L})$ and agitation speed $(200 \mathrm{rpm})$ were $90 \mathrm{~min}, 8$, and $3 \mathrm{~g} / 100 \mathrm{~mL}$, respectively. The experimental data were found to fit the Freundlich isotherm model. The maximum adsorption capacity of fluoride on WGB was $1.1 \mathrm{mg} / \mathrm{g}$. The continuous mode experiments clearly confirmed the important role of WGB bed in hindering and confining the propagation of the fluoride-loaded plume as well as there was a very good matching (RMSE $\leq 0.0398$ ) with the predicted results obtained by the simulated mathematical model using COMSOL Multiphysics 3.5a software.
\end{abstract}

Keywords: Defluoridation, Fluoride adsorption, Recycling Waste granular brick, Water treatment

\section{Introduction}

Fluoride is the $13^{\text {th }}$ most abundant naturally occurring element which is reactive and electronegative. In drinking water fluoride has a beneficial effect on teeth in low concentration. Exposure to excessive fluoride concentration can cause irreversible demineralization of tooth and bone tissues, a condition known as fluorosis, and long-term damage to liver, brain, thyroid, and kidney [1-4]. According to WHO, the acceptable level of fluoride in safe drinking water is ranged from 0.5 to $1.0 \mathrm{mg} / \mathrm{L}$ [5-7]. Many defluoridation techniques were adapted by several nations in 1930's to investigate the negative effect of excess fluoride in drinking water and work on methods to remove excess fluoride [8-10]. The surface adsorption maintains a great place in the research and practice of defluoridation because of its general approachability and feasibility. A wide range of materials were utilized for fluoride adsorption including lime followed by zirconium as a polishing step [11], red mud [12], amended clay [13] activated alumina, alum, and brick powder [14-16], hydrous iron III0-tin (IV) bimetal mixed oxide [5], modified bentonite clay [17], polymer/biopolymer composites [6], acidic alumina [18, 19], wheat dust, sawdust, and activated bagasse carbon of sugarcane [20], bone char [21], alum impregnated brick powder [22], citrus limonum leaf [23], raw unmodified bones [24], calcite nanoparticles [25], bio-adsorbent [26-27], laterite soil based adsorbents [28], neem oil-phenolic resin treated plant bio-sorbent [29], calcium carbonate [30-31], layered ZSM-5 zeolite [32], Ni and $\mathrm{Zn}$ modified LD slag based geopolymer [33]. In general, the majority of these adsorbent materials were used in batch mode experiments, while its column run was seldom studied. Waste brick material is one of these materials in which its performance and efficiency for fluoride and some other inorganic species uptake was widely investigated in batch mode assays. Kumar et al. [34] studied the defluoridation of groundwater using brick powder in batch experiments.

The elimination of fluoride was found to be 48.73 and $56.4 \%$ from groundwater samples having 3.14 and $1.21 \mathrm{mg} \mathrm{F} / \mathrm{l}$, respectively, under the optimized conditions of $\mathrm{pH}$, effect of dose, and contact time. Wijesundara et al. [35] used broken bricks as defluoridating agent for development of a low cost domestic defluoridator for rural area. The removal rate of fluoride was far
This is an Open Access article distributed under the terms of the Creative Commons Attribution Non-Commercial License (http://creativecommons.org/licenses/by-nc/3.0/) which permits unrestricted non-commercial use, distribution, and reproduction in any medium, provided the original work is properly cited.
Received December 19, 2019 Accepted April 29, 2020

${ }^{\dagger}$ Corresponding author

Email: zismail9@gmail.com,zismail3@gatech.edu Tel: +9647709023240 
better in small pieces than large pieces of broken bricks. Singh et al. [36] used suggested $29.8 \%$ to $54.4 \%$ removal efficiency of fluoride from aqueous solution and ground water, respectively using brick powder at $\mathrm{pH}$ of 6-8 and adsorbent dose of 0.6-1.0 g/L when the contact time was increased from 15 to $120 \mathrm{~min}$. Rani et al. [15] suggested the use of brick powder for fluoride removal from aqueous solution and ground water. Jain and Singh [22] used alum impregnated brick powder (AIBP) for defluoridation of water. The removal of fluoride by AIBP was $4.0-5.0 \%$ higher than that of brick powder (BP). Bibi [37] used hydrated cement, brick powder, and arble powder wastes for fluoride and arsenic removal from water. Kumar et al. [38] assessed in batch experiments the suitability of commercially available bricks powder used in fluoride-contaminated water. Maximum removal of fluoride was observed to be $94 \%$ at optimum conditions. Rafique et al. [39] evaluated the fluoride adsorption onto the red brick paving blocks which is available as a cost effective potential adsorbent for defluoridation. The highest percentage removal of fluoride in batch mode experiments was $62 \%$ achieved at $\mathrm{pH}$ range of 6-7.

The previously reported studies suggested using waste brick powder rather than granular waste brick. However, to the authors' knowledge no previous studies were reported concerned of assessing the experimental and predicted performance of waste granular brick in a column test for fluoride removal.

This study aimed to investigate the potential of waste granular brick (WGB) for water defluoridation in a fixed bed column. A modeling study was performed using COMSOL Multiphysics 3.5a software to predict the behavior of the suggested system comparatively to experimental findings.

\section{Material and Methods}

\subsection{Adsorbent}

Raw waste granular brick (WGB) was used for fluoride adsorption from aqueous solution as inexpensive unused substance. WGB was obtained by collecting waste bricks from different local demolition locations. The collected waste bricks were crushed into smaller size granules using manual hammer, sieved, repeatedly washed with distilled water, Then dried in oven at $105^{\circ} \mathrm{C}$ for $24 \mathrm{~h}$. Particles size ranged from 1 to $2 \mathrm{~mm}$ with an average of $1.414 \mathrm{~mm}$ was utilized for the adsorption assays.

\subsection{Fluoride-loaded Aqueous Solution}

Fluoride-loaded aqueous solution having concentration of $10 \mathrm{mg} / \mathrm{L}$ was prepared by dissolving the desired quantity of sodium fluoride $(\mathrm{NaF})$ in distilled water. The residual concentration of fluoride ions $\left(\mathrm{F}^{-}\right)$in the treated solutions was determined by using a combined ion selective electrode (Ion lab pH/Ion/Cond 750, WTW). Additional cross checking was carried out using different type of separate Ion Selective Electrode (Model Orion). For, more accuracy, triple-checking of fluoride concentrations were achieved by means of ion chromatography (Model: Metnohm Swiss 881 compact IC 2008).

\subsection{Batch Experiments for Fluoride Sorption}

The batch experiments for fluoride uptake were conducted at room temperature $\left(28 \pm 2^{\circ} \mathrm{C}\right)$. These experiments were carried out by agitation of $100 \mathrm{ml}$ - fluoride solutions at initial concentration of $10 \mathrm{mg} / \mathrm{L}$ in $250 \mathrm{ml}$-plastic Erlenmeyer flasks using different amounts of WGB including 0.2, 0.5, 0.75, 1.0, 1.5, 2.0, 2.5, 3.0, 4.0, and 5.0 g. Several contact times of 5, 10, 15, 30, 60, 90,120 , and $180 \mathrm{~min}$ was carefully considered in this study. After proper predetermined time intervals, supernatant samples were filtered and analyzed to determine the remaining concentration of fluoride ions. Also, the $\mathrm{pH}$ adjustment was performed for various values at a range from 3 to10 by the addition of 1 $\mathrm{M} \mathrm{NaOH}$ or $1 \mathrm{M} \mathrm{HCl}$. All experiments were carried out in duplicate. The quantity of adsorbed fluoride $\left(\mathrm{q}_{\mathrm{e}}\right)$ was calculated as in Eq. (1) [40].

$$
q_{e}=\left(C_{0}-C_{e}\right) \frac{V}{m}
$$

Where, $\mathrm{C}_{o}$ and $\mathrm{C}_{\mathrm{e}}$ are the initial and equilibrium concentrations of fluoride in the solution $(\mathrm{mg} / \mathrm{L}), \mathrm{V}$ is the volume of solution (L), and $\mathrm{m}$ is the mass of the adsorbent WGB (g).

\subsection{Column Test Assays}

The schematic diagram of the experimental system used in this study is given in Fig. 1. The cylindrical adsorption column was made of Perspex material of dimensions 85 and $10 \mathrm{~cm}$ for the height and diameter, respectively. The column was packed with WGB, and supplied with seven nozzles to take samples at a distance

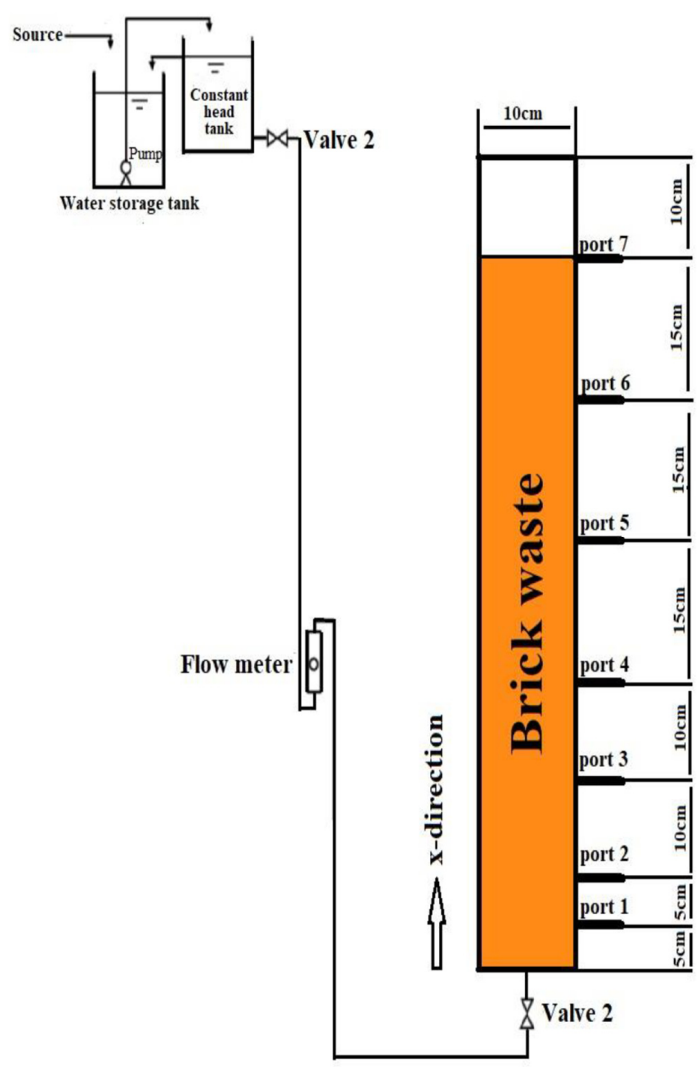

Fig. 1. Schematic diagram of the lab-scale adsorption column. 
of $5,10,20,30,45,60$, and $75 \mathrm{~cm}$ for nozzles $1,2,3,4,5,6$, and 7 , respectively from the bottom of the column. Samples were withdrawn from the column bed by inserting a needle into the center of the column at specific time intervals. First of all, to ensure that air was expelled from the column, distilled water was injected into the bottom of the adsorption column upward through the WGB bed. Then after, the fluoride-loaded solution was introduced into the column using an elevated feed tank. The flow of fluoride-loaded solution from the feed tank to the adsorption column was controlled using two valves (valves 1 and 2) and a flow meter as given in Fig. 1. The flow rate values of the fluoride-bearing solution were 15 and $25 \mathrm{ml} / \mathrm{min}$. Monitoring of the fluoride concentration along the column throughout the sampling ports was carried out along a period of 15 days. Samples were analyzed for residual fluoride at different time intervals including 1, 5, 10, and 15 days.

\subsection{Characterization of WGB and Chemical Analysis}

Fourier transform infrared spectroscopy (FT-IR) was carried out to characterize the presence of functional groups on the surface of fresh and spent WGB using FT-IR spectrometer (Type: EQUINOX FT-IR 55).

Scanning Electron Microscope (TESCAN Vega III) V was used for the surface studies of WGB material. The fluoride-loaded residue was filtered, washed, dried at $105^{\circ} \mathrm{C}$ for $30 \mathrm{~min}$, and then cooled to room temperature. Fluoride-free residue was also subjected to the same conditions and both types of residues was analyzed by SEM to determine the variations on the mass surface after and before loading by the fluoride species. The micrographs were at resolution of 10000x. SEM of virgin and fluoride-loaded WGB samples were useful to assess their surface characteristics after determining the optimal conditions for adsorption. An Energy Dispersive $\mathrm{X}$-Ray Analyzer (EDX) is a potential tool for investigating the distribution of minerals and also the effect of the elements on this distribution. In this study EDX analysis was carried out for providing the desired elemental identification and quantitative compositional information.

\subsection{Adsorption Isotherms}

In this study, two isotherm models Freundlich and Langmuir as given by Eqs. (2) and (3) were used to fit the experimental data. The Langmuir model assumes monolayer adsorption while the Freundlich model is empirical in nature which assumes the adsorption is heterogeneous on the surface.

$$
\begin{gathered}
q_{e}=K_{F} C_{e}^{1 / N} \\
q_{e}=\frac{q_{m} b C_{e}}{1+b C_{e}}
\end{gathered}
$$

Where:

$\mathrm{C}_{\mathrm{e}}$ is the remaining concentration of fluoride in the aqueous solution at equilibrium ( $\mathrm{mg} \mathrm{F} / \mathrm{L}$ ), $\mathrm{q}_{\mathrm{e}}\left(\mathrm{mg} \mathrm{F}^{-} / \mathrm{g}\right)$ is the mass adsorbed per unit mass of WGB at equilibrium, $\mathrm{q}_{\mathrm{m}}$ is the amount of fluoride adsorbed per unit of adsorbent for a monolayer surface and $\mathrm{b}$ is the constant related to the free energy of adsorption. $\mathrm{K}_{\mathrm{F}}$ (mg/g) (l/mg) ${ }^{1 / N}$ is the Freundlich sorption coefficient and $\mathrm{N}$ is an empirical coefficient indicative of the intensity of the adsorption.

\section{Modeling Study}

\subsection{Transport of Contaminant through the Model Adsorption Column}

In this study, a one-dimensional (ID) system model was considered. Hence, the migration and transport of fluoride ions in the porous WGB is due to the advection-dispersion processes can be represented by Eq. (4) as cited by Faisal and Abd Ali [26]:

$$
D_{x} \frac{\partial^{2} C}{\partial x^{2}}-V_{x} \frac{\partial C}{\partial x}=\frac{\partial C}{\partial t}+\frac{\rho_{b}}{\theta} \frac{\partial(q)}{\partial t}
$$

Where:

$\mathrm{D}_{\mathrm{x}}$ is the hydrodynamic dispersion coefficient in the $\mathrm{x}$-direction $\left(\mathrm{m}^{2} / \mathrm{s}\right), V_{\mathrm{x}}$ is the seepage velocity in the $\mathrm{x}$-direction $(\mathrm{m} / \mathrm{s}), \mathrm{x}$ represents the distance in the $\mathrm{x}$-direction $(\mathrm{m}), \mathrm{C}$ is the fluoride concentration in water, $\mathrm{q}$ is the fluoride concentration sorbed on the adsorbent $(\mathrm{mg} / \mathrm{kg}), \theta$ is the porosity of the media (WGB), and $\rho_{\mathrm{b}}$ is the dry adsorbent bulk density $\left(\mathrm{kg} / \mathrm{m}^{3}\right)$.

Under equilibrium isothermal conditions, the term (q) on the right side of Eq. (4) can be substituted by Eq. (2), since the experimental results of the batch test fitted very well with Freundlich isotherm, accordingly Eq. (2) can be combined with Eq. (4) as follows:

$$
D_{x} \frac{\partial^{2} C}{\partial x^{2}}-V_{x} \frac{\partial C}{\partial x}=\frac{\partial C}{\partial t}+\frac{\rho_{b}}{\theta} \frac{\partial\left(K_{F} C^{(1 / N)}\right)}{\partial t}
$$

This equation can be simplified as:

$$
D_{x} \frac{\partial^{2} C}{\partial x^{2}}-V_{x} \frac{\partial C}{\partial x}=\left(1+\frac{\rho_{b} K_{F}}{\Theta N} C^{\left(\frac{1-N}{N}\right)}\right) \frac{\partial C}{\partial t}
$$

The effect of hindering or delaying the transport of $\mathrm{F}^{-}$ions in relation to the advection front can be defined by the retardation factor $\left(R_{F}\right)$ as in Eq. (7):

$$
R_{F}=1+\frac{\rho_{b} K_{F}}{\theta N} C^{\left[\frac{1-N}{N}\right]}
$$

Accordingly, the one-dimensional advection-dispersion equation that consider sorption into account for the equilibrium state of contaminant transport in the saturated zone can be written as follows:

$$
D_{x} \frac{\partial^{2} C}{\partial x^{2}}-V_{x} \frac{\partial C}{\partial x}=R_{F} \frac{\partial C}{\partial t}
$$

The initial liquid and $\mathrm{F}^{-}$concentrations are assumed to be zero throughout the entire flow domain, and the boundary conditions used are reported as follows: 
Lower boundary $(\mathrm{x}=0): \mathrm{C}=10 \mathrm{mg} / \mathrm{L}$

Upper boundary $(\mathrm{x}=75 \mathrm{~cm})$ : advective flux (i.e. $\frac{\partial \mathrm{C}}{\partial \mathrm{x}}=0$ )

To present a numerical solution, Eq. (8) in combination with initial and boundary conditions can be solved using COMSOL Multiphysics 3.5a software.

\subsection{Longitudinal Dispersion Coefficient and Tortuosity}

The effect of hydrodynamic dispersion is to cause a plume of contamination to extend in the direction of advection as well as to create a gradient of declining concentration from the center to the boundaries of the plume. However, the values of longitudinal dispersivity $\left(\alpha_{\mathrm{L}}\right)$ used in the present study for WGB adsorbent was calculated using the Eq. (10) [41]:

$$
\alpha_{L}=0.83(\log L)^{2.414}
$$

Where: $\mathrm{L}$ is the length of the flow path $(\mathrm{cm})$.

Tortuosity is a measure of the influence of water molecules flow path in porous media. It is calculated depending on the porosity of the medium () as follows [42]:

$$
\tau=(\theta)^{m-1}
$$

As cited by Holzbecher [42], Archie in 1942 reported the values of $\mathrm{m}$ in the range of 1.8 - 2 for consolidated sandstones, 1.3 for unconsolidated sand in a laboratory experiment, and 1.3 - 2 for partly consolidated sand. For theoretical or conceptual work the value $m=2$ was considered, which could be justified if there is no further information available.

\section{Results and Discussion}

\subsection{Results of WGB Characterization}

\subsubsection{FT-IR analysis}

The results were considered by comparing the FT-IR spectra of fresh WGB with the fluoride-bearing WGB (spent WGB). The difference between FT-IR spectrum of GWB before and after fluoride adsorption demonstrated the decrease of transmittance percentage in the range of $850-4,000 \mathrm{~cm}^{-1}$ and shifting of the peaks in the post sorption spectrum (Fig. 2). The FTIR spectrum before fluoride removal indicates the presence of a broad and strong band of phosphate, PO4 $4^{-3}$ group $\left(1,100-900 \mathrm{~cm}^{-1}\right)$, carbonate of $\mathrm{CO}^{-2}\left(720 \mathrm{~cm}^{-1}\right)$, and a broad and strong band of calcium of $\mathrm{Ca}^{+2}\left(550-610 \mathrm{~cm}^{-1}\right)$. The main functional groups, phosphate and calcium groups after fluoride uptake, the peak $\mathrm{Ca}^{+2}\left(550-610 \mathrm{~cm}^{-1}\right)$ changed, was not strong and broad or was substantially lower than that before removal, suggesting some participation of $\mathrm{Ca}^{-2}$ in the binding of fluoride by the bones and some dissolving in the solution, also phosphate peak, $\mathrm{PO}^{-3}\left(1,100-900 \mathrm{~cm}^{-1}\right)$, changed was strongest than calcium due to elution in to solution as it the main exchangeable ions in bone structure with fluoride.

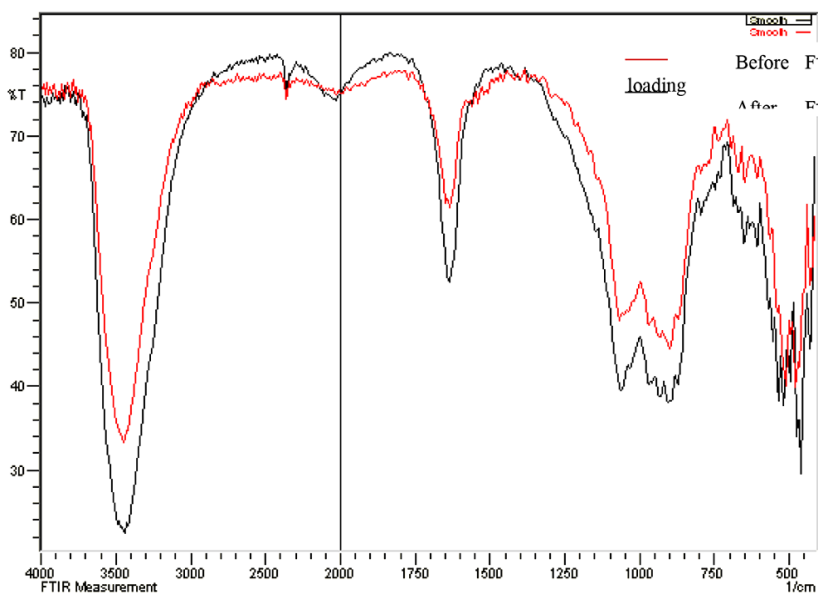

Fig. 2. FT-IR of brick waste before and after fluoride loading.

Additionally, the new peaks are emerged at few wavelengths (450 and $600 \mathrm{~cm}^{-1}$ ) after fluoride adsorption. The fresh WGB showed peaks at 2,360, 1,635.64 and 1,064.71 $\mathrm{cm}^{-1}$ due to $\mathrm{O}-\mathrm{H}$ bending vibration [19].

After $\mathrm{F}^{-}$ions sorption those peaks shifted to 2365, 1634, and 1050, respectively, indicating that $\mathrm{F}^{-}$ions interaction with WGB is due to the contribution of ion exchange process. The shifting of the peaks at 929.69, 906.54, and $748.38 \mathrm{~cm}^{-1}$ to $940.50,900.10$, and $750.55 \mathrm{~cm}^{-1}$, respectively, is probably due to the interaction of WGB and $\mathrm{F}^{-1}$ ion by electrostatic attraction. The shift of peak at $651.99 \mathrm{~cm}^{-1}$ to $655 \mathrm{~cm}^{-1}$ could be due to the lattice vibration mode [43, 44].

\subsubsection{SEM and EDX analysis}

The Scanning Electron Microscopy (SEM) analysis was used to study the surface morphology of the adsorbents. Fig. S1 showed fluoride-loaded and fresh mass of WGB. Fig. S1(a) demonstrated that WGB had disparate surfaces with significant pores spaces, which could offer extended sites for physical or chemical adsorption of $\mathrm{F}^{-}$ions. Fig. S1(b) indicated that the pores were completely wrapped due to the assumption that adsorption and accumulation of fluoride from layers which settled on the irregular jagged surfaces. The data which is generated by EDX analysis consists of spectra with peaks corresponding to the different elements in the WGB sample. EDX spectra of WGB given in Fig.S2 shows the elemental composition of WGB which indicates the presence of $\mathrm{O}, \mathrm{Ca}, \mathrm{Si}$, $\mathrm{Al}, \mathrm{Fe}, \mathrm{Mg}, \mathrm{Na}, \mathrm{K}$, and $\mathrm{S}$.

\subsection{Fluoride Removal}

So as to investigate the optimum favorable conditions for maximum fluoride removal using WGB as a sorbent material, the effect of contact time, $\mathrm{pH}$, and WGB dose were carefully considered in this study as the key parameters. However, a set of preliminary batch experiments were carried out to investigate the effect of agitation rate on fluoride uptake by WGB. The results (data not shown) demonstrated that no tangible effect was observed and the percentages removal of fluoride was comparable using four different agitation rates including 100, 150, 200, and $250 \mathrm{rpm}$. Accordingly, 200 rpm was applied in all batch experiments because 
at this speed, the removal efficiency was relatively the highest, then, it remained stable in spite of increasing the speed, under the experimental conditions.

\subsubsection{Effect of contact time}

The times of equilibration in the range of 5-180 min were carried out as a set of batch experiments to estimate the time duration required to achieve equilibrium. The results demonstrated that the process of fluoride removal by WGB was relatively a rapid process. The biphasic profile of the fluoride removal involved two sections; a rapid removal rate within $30 \mathrm{~min}$ followed by slow removal rate until achieving equilibrium at $90 \mathrm{~min}$ as given in Fig. 3(a). The effect of contact time on the fluoride removal by WGB was determined using initial concentration of $10 \mathrm{mg} \mathrm{F}^{-} / \mathrm{L}$, $\mathrm{pH} 6$, and $0.5 \mathrm{~g} / 100 \mathrm{~mL}$ of WGB.

\subsubsection{Effect of $\mathrm{pH}$}

The $\mathrm{pH}$ of the aqueous solution is a vital essential parameter that effects the sorption of ions at the solid-liquid interfaces. The effect of $\mathrm{pH}$ on fluoride adsorption onto WGB surface was determined via sets of experiments that used initial fluoride concentration of $10 \mathrm{mg} \mathrm{F} / \mathrm{L}$ and maintaining $\mathrm{pH}$ at values of $3,4,5,6,7,8$, 9, and 10. Fig. 3(b) presents the effect of $\mathrm{pH}$ on the fluoride adsorption onto the WGB. The results demonstrated that the uptake of fluoride species increased with increasing the $\mathrm{pH}$. However, at $\mathrm{pH}$ values higher than 8, the removal efficiency of fluoride ions decreased. This could be assigned to the fact that the sorbent surface sites at higher $\mathrm{pH}$ will take more negative charges symbolized by $\mathrm{OH}$ ions which would meaningfully reject the negatively charged Fions in the solution.

\subsubsection{Effect of WGB dose}

One of the important factors that affect the sorption equilibrium is the sorbent dose. As mentioned earlier in section 2.3, several doses of WGB were applied in this study to determine the optimum dose for best removal of fluoride. The results revealed that $3 \mathrm{~g}$ of WGB was the optimum value for a highest removal efficiency of fluoride up to $82 \%$ at $\mathrm{pH} 8$ and 90 min contact time as shown in Fig. 3(c). Increasing the WGB dose will lead to increase of fluoride uptake capacity. This could be assigned to the fact that more sorbent surfaces or more active sites were available for the fluoride uptake by increasing the WGB dose. These results demonstrated a pretty agreement with the profile of fluoride sorption onto natural clay as reported by Ramdani et al. [44]. However, when the dose of the adsorbent exceeds $3 \mathrm{~g} / 100 \mathrm{~mL}$, the fluoride removal efficiency didn't exhibit an obvious increase. This observation could be due to the mass transfer resistance of fluoride species from the bulk of the solution to the WGB surfaces. This could explain that once equilibrium was achieved, a constant pattern of the fluoride percentage uptake will be clearly observed. It seems that increasing the WGB amounts will cause them to lay up over one another and reduce the active site for sorption [32, 45].
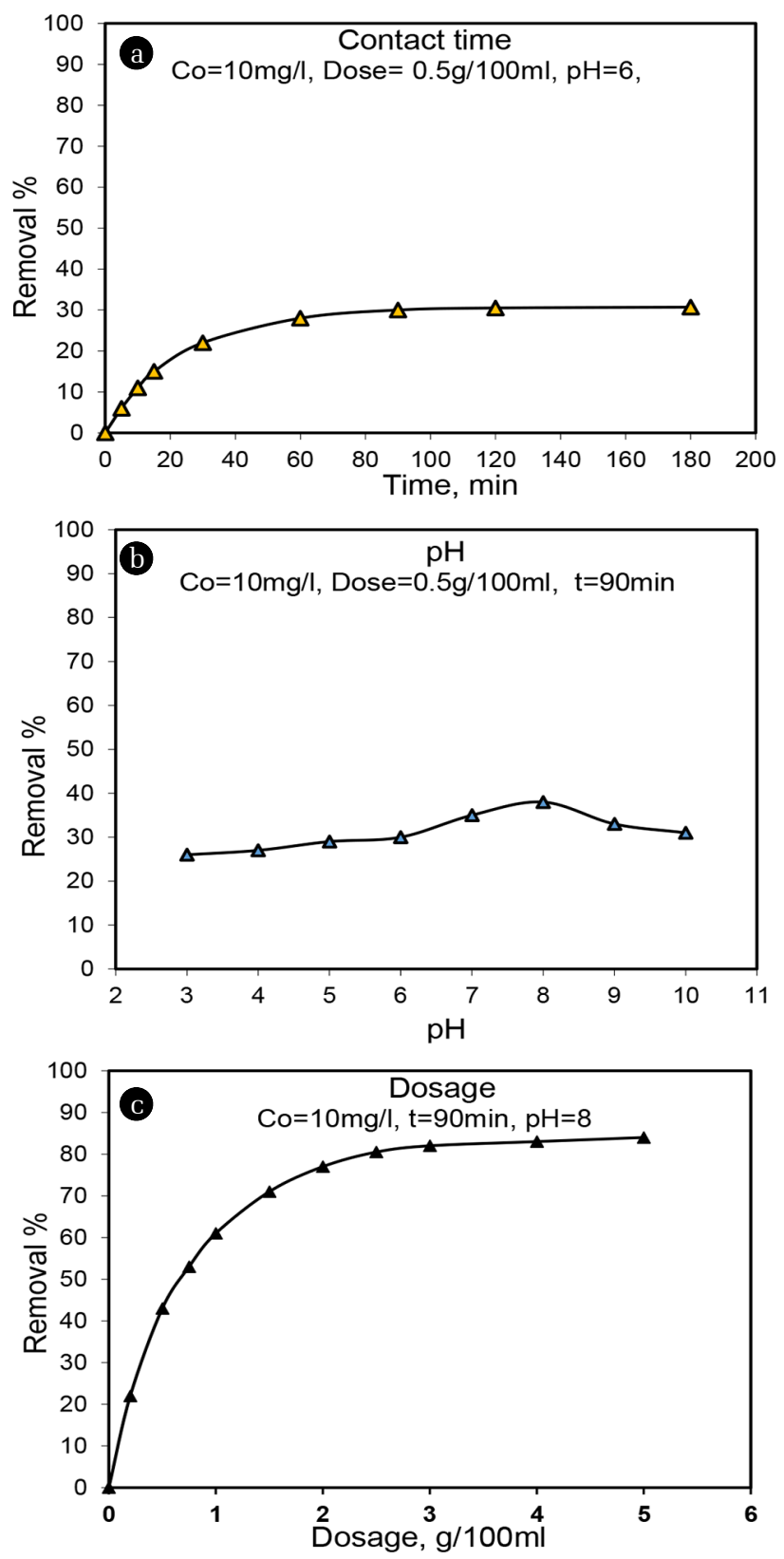

Fig. 3. Profile of fluoride removal percent at different (a) Contact times, (b) $\mathrm{pH}$, and (c) Dosage.

\subsection{Sorption Isotherms}

As mentioned earlier, the experimental adsorption data were fitted with Freundlich and Langmuir isotherm models. Table 1 illustrates the constants values estimated using the linear form of the isotherm

Table 1. Estimated Parameters for Freundlich and Langmuir Sorption Isotherms

\begin{tabular}{lcccccc}
\hline \multirow{2}{*}{ Isotherm } & \multicolumn{3}{c}{ Freundlich } & \multicolumn{3}{c}{ Langmuir } \\
\cline { 2 - 6 } & $\boldsymbol{K}_{\boldsymbol{F}}$ & $\boldsymbol{N}$ & $\boldsymbol{R}^{2}$ & \multicolumn{2}{c}{$\boldsymbol{q}_{\boldsymbol{m}}$} & $\boldsymbol{b}$ \\
\hline Estimated parameters & 0.1927 & 1.1997 & 0.9565 & $8.8573 \mathrm{mg} / \mathrm{g}$ & $0.0186 \mathrm{~L} / \mathrm{mg}$ & 0.5380 \\
\hline
\end{tabular}




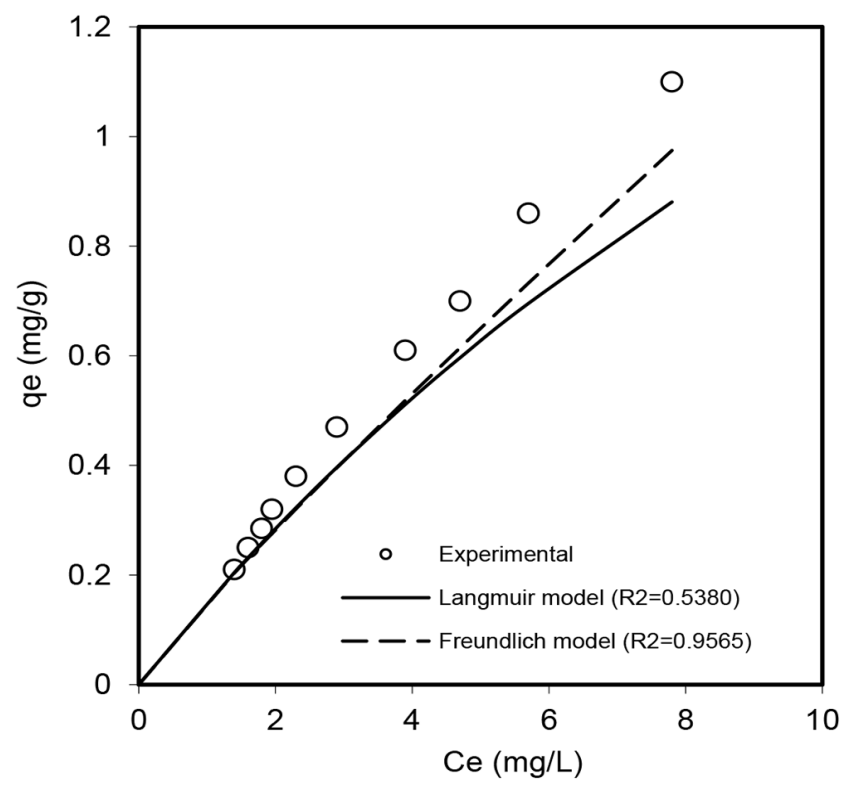

Fig. 4. Plots of the adsorption isotherms.

models. It has been noticed that values of the coefficient of determination $\left(\mathrm{R}^{2}\right)$ were potentially higher for Freundlich model compared with the same for Langmuir model suggesting applicability of Freundlich isotherm model as shown in Fig. 4.

The constant $N$ provides an indication of how favorable the adsorption processes were. According to Valko et al. [46], the slope $1 / N$ is the measure of adsorption intensity or surface heterogeneity which represents the deviation from linearity of adsorption as follows: if the value of $1 / N=1$, the adsorption is linear, $1 / N<1$, it is a chemical adsorption process, if $1 / N>1$, the adsorption is a favorable physical process and it is cooperative. Hence, in this study the value of $1 / N$ was found to be 0.8335 , indicating that the fluoride adsorption onto WGB was chemical and based on the fact that the Freundlich isotherm model describes the physicochemical adsorption onto the heterogeneous surfaces as reported by Chassapis et al. [47].

\subsection{Column Test}

The effect of bed thickness varied from 0.05 to $0.75 \mathrm{~m}$ in the down gradient of the bed for at flow rate of $20 \mathrm{ml} / \mathrm{min}$ is showed in Fig. 5. It is obvious that WGB bed exhibits better $\mathrm{F}^{-}$uptake with increasing its thickness. This is due to the fact that $\mathrm{F}$ - loaded solution has a higher retention time which permits a best adsorption process. However, it seems that this WGB bed started saturation with increasing the travel time. This indicated that the $\mathrm{F}$ retardation factor $\left(R_{F}\right)$ was reduced, and a decrease in the WGB functionality towards $\mathrm{F}^{-}$ions removal was occurred. The performance of WGB bed could be defined as the required duration to keep the concentration of pollutant down gradient of the bed as less than the maximum fluoride level (MFL) that could be present in drinking water $\left(0.001 \mathrm{~kg} / \mathrm{m}^{3}\right)$ [7]. The performance of WGB bed increased with increasing its thickness, for example, the bed of thickness $0.75 \mathrm{~m}$ had a higher operation time up to 13 days in comparison with $0.3 \mathrm{~m}$ bed thickness which had an operation time of 4 days, since

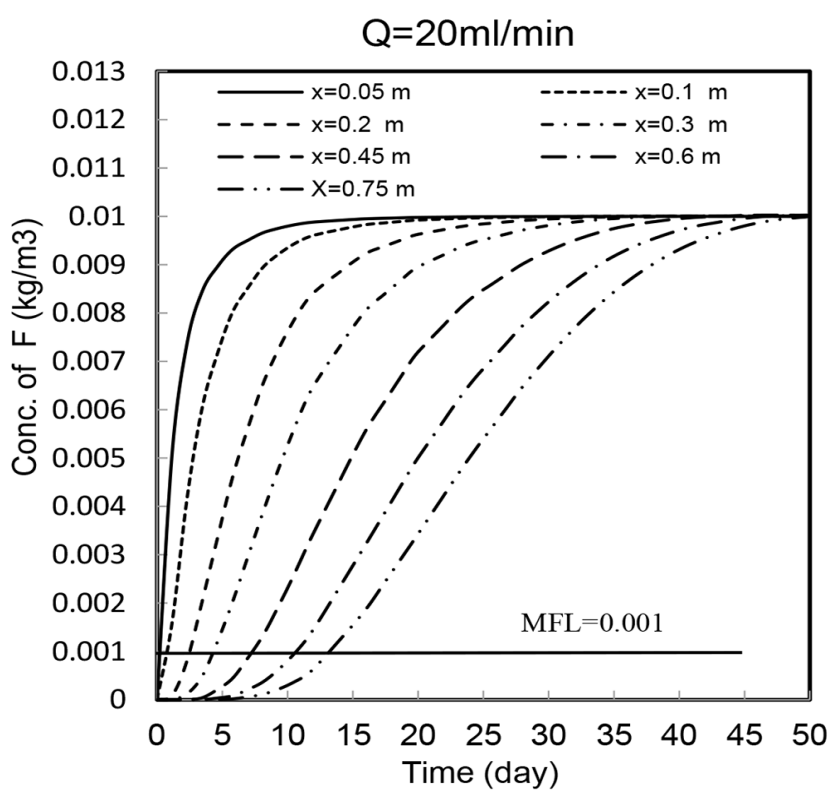

Fig. 5. Relationship of fluoride concentration and time within the thickness of the WGB bed.

the outflow of $\mathrm{F}^{-}$ions concentration from the $0.3 \mathrm{~m}$-thickness bed achieved maximum fluoride level faster than the bed of thickness $0.75 \mathrm{~m}$ as illustrated in Fig. 5 .

The profiles of fluoride concentration predicted by COMSOL software along the WGB fixed bed column $(\mathrm{x}=0.75 \mathrm{~m})$ at flow rate values of 5, 10, and $20 \mathrm{~mL} / \mathrm{min}$ are given in Fig. 6 at several time intervals. This figure demonstrates the importance role of WGB bed in hindering and confining the propagation of the fluoride-loaded plume. Moreover, it seems that the propagation of the contaminant front will increase with increasing the flow rate.

\subsection{Experimental and Predicted Results}

The predicted and experimental results for the adsorption of fluoride were compared during the migration of the contaminant plume at different time periods and flow rates 15 and $25 \mathrm{~mL} / \mathrm{min}$ along the adsorption column as depicted in Fig. 7. It is obvious that there is a good matching between the predicted and experimental results. Additionally, the root mean squared error (RMSE) was used in this study as a statistical tool to find the degree of agreement between these values [48]. Values of RMSE were $\leq 0.0398$ confirming a very good agreement between predicted and measured values.

\subsection{The Prospects for Recycling Brick Waste Material}

The application of available cost effective or no cost materials for the removal of numerous pollutants including fluoride removal from wastewater has been widely studied during recent years. All over the world, especially in the developing countries, brick waste are available in excessive amounts as abundant demolition wastes materials. These waste products can be recycled in a wholly practical and ecological manner, thus reducing pollution and benefiting 

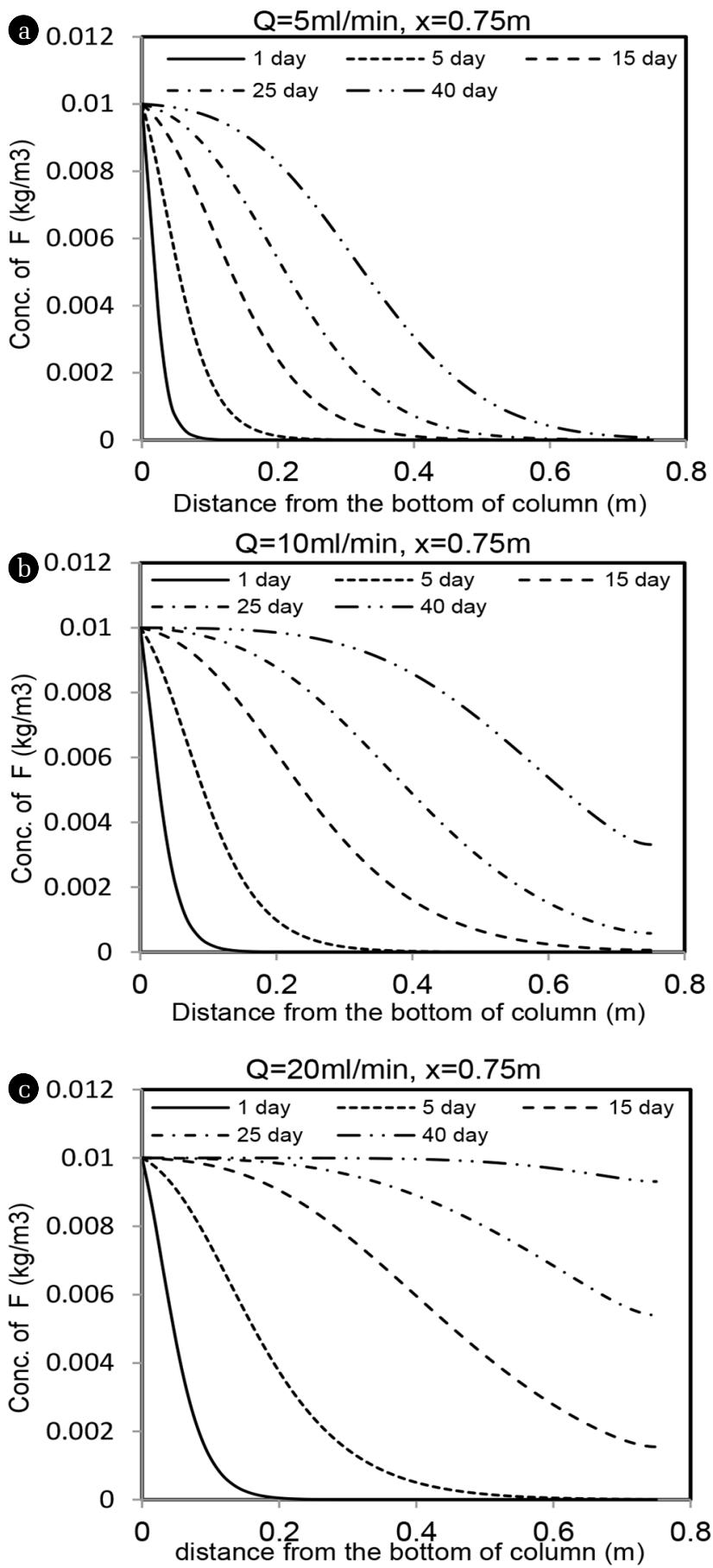

Fig. 6. Calculated concentration of $\mathrm{F}$ - along with the length of the column at different flow rates.

the environment and the economy by reducing waste as well. Results obtained in this study indicate that the granular brick waste materials could be successfully applied for fluoride removal from water. A comparison between the removal efficiency of fluoride by the granular brick waste and different adsorbents reported in previous studies are presented in Table S1.
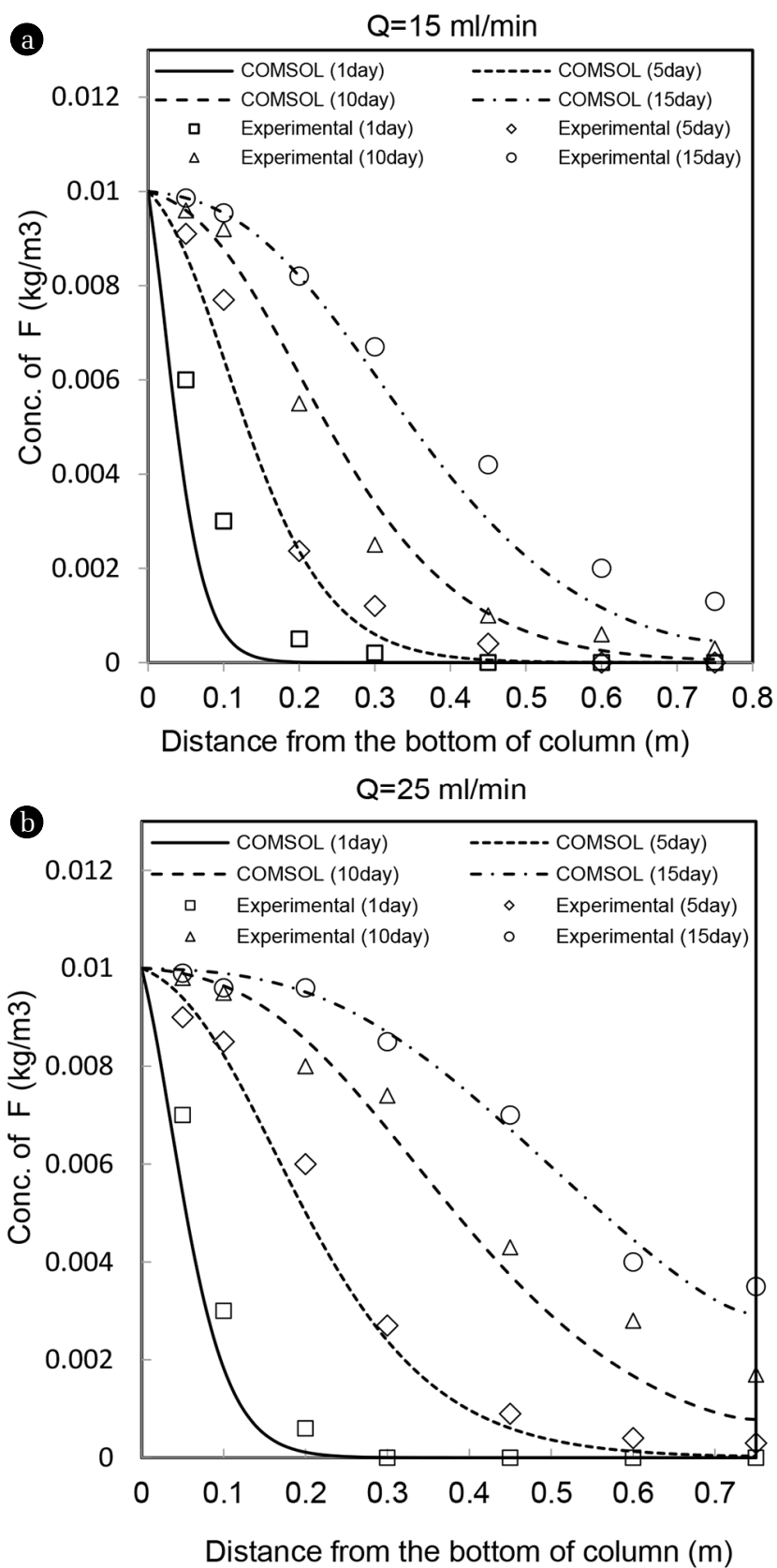

Fig. 7. Comparison between the predicted and experimental results.

\section{Conclusions}

This study investigated the ability of new application of waste granular brick (WGB) for fluoride uptake from aqueous solutions in fixed bed running in a continuous mode. The approach was reliable, easy to be applied with a significant potential for fluoride removal. Results revealed that unmodified WGB can be used effectively for fluoride removal from aqueous solution. Batch test results demonstrated that maximum removal efficiency of fluoride was found to be $82 \%$ using $10 \mathrm{mg} / \mathrm{L}$ initial concentration of $\mathrm{F}^{-1}$, WGB 
dose of $3 \mathrm{~g} / 100 \mathrm{~mL}$ at $\mathrm{pH} 8$ and contact time $90 \mathrm{~min}$. The adsorption followed the Freundlich adsorption isotherm model with a coefficient of determination 0.9565. Results of the column test demonstrated that the performance of WGB fixed bed for fluoride removal increased with increasing the bed thickness. A very good agreement between predicted and measured values was observed. This study is extended to investigate: (1) the potential approach for regeneration of the exhausted fluoride-bearing adsorbent, (2) the application of the suggested adsorbent for fluoride removal from real samples of groundwater and wastewater.

\section{Acknowledgment}

The authors are thankful to the staff of Ministry of Science and Technology for their technical support. No fund or specific grant has been received for this research study.

\section{Author Contributions}

Z.T.A-A (Associate professor) conducted part of the experimental work, carried out the simulation work using the COMSOL software, and participated in writing the manuscript. Z.Z.I (Professor) suggested the research technical plan, carried out part of the experimental work, wrote the manuscript and revised it.

\section{References}

1. Mobeen N, Kumar P. Defluoridation techniques- A Critical review. Asian J. Pharm. Clin. Res. 2017;10:64-71.

2. Yousefi M, Ghalehaskar S, Asghari, FB, et al. Distribution of fluoride contamination in drinking water resources and health risk assessment using geographic information system, northwest Iran, Regul. Toxicol. Pharmacol. 2019;107:104408.

3. Amini H, Haghighat GA, Yunesian M, et al. Spatial and temporal variability of fluoride concentrations in groundwater resources of Larestan and Gerash regions in Iran from 2003 to 2010. Environ. Geochem. Health. 2016;38:25-37.

4. Ismail ZZ, Abdlekareem HN. Uptake of fluoride from water using recycled raw beef bone as an environmentally friendly waste. J. Eng. 2013;19:1576-1585.

5. Biswas K, Gupta K, Ghosh UC. Adsorption of fluoride by hydrous iron (III)- tin (IV) bimetal mixed oxide from the aqueous solutions. Chem. Eng. J. 2009;149:196-206.

6. Karthikeyan M, Kumar KKS, Elango KP. Batch sorption studies on the removal of fluoride ions from water using eco-friendly conduct in polymer/biopolymer composites. Desalination 2011;267:49-56.

7. Swain SK, Mishra S, Patnaik T, Patel RK, Jha U, Dey RK. Fluoride removal performance of a new hybrid sorbent of Zr(IV)-ethylenediamine. Chem. Eng. J. 2012;184:72-81.

8. Mkongo FJ. Water defluoridation for rural fluoride affected communities in Tanzania. In: 1st International Workshop on Fluorosis Prevention and Defluoridation of Water, Ngurdoto, Tanzania. International Society for Fluoride Research; 1995.
9. Dehghani MH, Haghighat GA, Yousefi M. Data on fluoride concentration in drinking water resources in Iran: A case study of Fars province; Larestan region. Data in Brief. 2018;19:842-846.

10. Dehghani MH, Zareic A, Yousefi M, Asghari FB, Gholam Ali Haghighat GA. Fluoride contamination in groundwater resources in the southern Iran and its related human health risks. Desalin. Water Treat. 2019;153:95-104.

11. Babu CA, Ayengar B, Lal KB, Amalraj RV. Removal of fluoride from pickling waste with zirconium. Waste Manag. 1993;13: 279-283.

12. Yunus C, Esengul K, Mustafa E. Removal of fluoride from aqueous solution by using red mud. Sep. Purif. Technol. 2002;28: 81-86.

13. Agarwal M, Rai K, Shrivastav R, Dass S. Deflouridation of water using amended clay. J. Clean. Prod. 2003;11:439-444.

14. Asheesh KY, KaushikC P, Anil KH, Ankur K, Neetu R. Defluoridation of ground water using brick powder as an adsorbent. J. Hazard. Mater. 2006;B128:289-293.

15. Rani B, Maheshwari R, Chauhan AK, Bhaskar NS. Defluoridation of contaminated water employing brick powder as an adsorbent. Int. J. Sci. Nat. 2012;3:78-82.

16. Ahamad KU, Singh R, Baruah I, Choudhury H, Sharma MR. Equilibrium and kinetics modeling of fluoride adsorption onto activated alumina, alum and brick powder. Groundwater Sust. Develop. 2018;7:452-458.

17. Kamble SP, Dixit P, Rayalu SS, Labhsetwar NK Defluoridation of drinking water using chemically modified bentonite clay. Desalination 2009;249:687-693.

18. Goswami A, Purkait MK. The defluoridation of water by acidic alumina. Chem. Eng. Res. Des. 2012;90:2316-2324.

19. Kumari U, Behera SK, Meikap BC. A novel acid modified alumina adsorbent with enhanced defluoridation property: kinetics, isotherm study and applicability on industrial wastewater. $J$. Hazard. Mater. 2019;365:868-828.

20. Kumar YA, Abbassi R, Dadashzadeh M. Removal of fluoride from aqueous solution and groundwater by wheat straw, sawdust and activated bagasse carbon of sugarcane. Ecol. Eng. 2013;52:211-218.

21. Rojas-Mayorga CK, Bonilla-Petriciolet A, Aguayo-Villarreal IA, et al. Optimization of pyrolysis conditions and adsorption properties of bone char for fluoride removal from water. J. Anal. Appl. Pyrolysis. 2013;104:10-18.

22. Jain A, Singh SK. Defluoridation of water using Alum impregnated brick powder and its comparison with brick powder. Int. J. Eng. Sci. Innov. Technol. 2014;3:591-596.

23. Tomar V, Prasad S, Kumar D. Adsorptive removal of fluoride from aqueous media using Citrus limonum (lemon) leaf. Microchem. J. 2014;112:97-103.

24. Ismail ZZ, AbdelKareem HN. Sustainable approach for recycling waste lamb and chicken bones for fluoride removal from water followed by reusing fluoride-bearing waste in concrete. Waste Manag. 2015;45:66-75.

25. Budyanto S, Kuo Y-L, Liu JC. Adsorption and precipitation of fluoride on calcite nanoparticles: A spectroscopic study. Sep. Purif. Technol. 2015;150:325-331.

26. Faisal AAH, Abd Ali ZT. Groundwater protection from lead contamination using granular dead anaerobic sludge biosorbent as permeable reactive barrier. Desalin. Water Treat. 2016;57: 
3891-3903.

27. Faisal AAH, Abd Ali ZT. Phenol removal using granular dead anaerobic sludge permeable reactive barrier in a simulated groundwater pilot plant. J. Eng. 2014;20:63-79.

28. Rathore VK, Mondal P. Life cycle assessment of defluoridation of water using laterite soil based adsorbents. J. Clean. Prod. 2018;180:716-727.

29. Manna S, Saha P, Roy D, Adhikari B, Das P. Fixed bed column study for water defluoridation using neem oil-phenolic resin treated plant bio-sorbent. J. Environ. Manag. 2018;212:424-432.

30. Wong EY, Stenstrom MK. Onsite defluoridation system for drinking water treatment using calcium carbonate. J. Environ. Manag. 2018;216:270-274.

31. Dehghani MH, Farhang M, Alimohammadi M., Mojtaba Afsharnia M, Mckay G. Adsorptive removal of fluoride from water by activated carbon derived from $\mathrm{CaCl}_{2}$-modified Crocus sativus leaves: Equilibrium adsorption isotherms, optimization, and influence of anions. Chem. Eng. Comm. 2018;205:955-965.

32. Přecha J, Bozhilovb KN, Fallaha JE, Barrierc N, Valtcheva V. Fluoride etching opens the structure and strengthens the active sites of the layered ZSM-5 zeolite. Microp. Mesop. Mat. 2019;280:297-305.

33. Sarkar C, Basu JK, Samanta AN. Experimental and kinetic study of fluoride adsorption by $\mathrm{Ni}$ and $\mathrm{Zn}$ modified $\mathrm{LD}$ slag based geopolymer. Chem. Eng. Res. Des. 2019;142,165-175.

34. Kumar YA, Kaushik CP, Haritash AK, Kansal A, Rani N. Defluoridation of groundwater using brick powder as an adsorbent. J. Hazard. Mater. 2005;128:289-293.

35. Wijesundara T. Low-cost defluoridation of water using broken bricks. In: 30th WEDC International Conference, Vientiane, Lao PDR; 2004.

36. Singh R. Raghuvanshi SP, Kaushik CP. Drinking water using brick powder as an adsorbent. Asian J. Chem. 2008;20:5818-5826.

37. Bibi S, Farooqi A, Hussain K, Haider N. Evaluation of industrial based adsorbents for simultaneous removal of arsenic and fluoride from drinking water. J. Clean. Prod. 2015;87:882-896.

38. Kumar N, Bansal N, Sharma SK. Fluoride removal using industrial waste: A case study of Jaipur city. Int. J. Curr. Eng.
Sci. Res. 2017;4:2394-0697.

39. Rafique T, Anas M, Chadhar KM, Soomro FY, Alvi S. Defluoridation of water by wasted red brick paving blocks. Desalin. Water Treat. 2018;108:207-215.

40. Wang S, Nan Z, Li Y, Zhao Z. The chemical bonding of copper ions on kaolin from Suzhou, China. Desalination. 2009;249: 991-995.

41. Fetter CW. Contaminant hydrogeology. 2nd edition. Prentice-Hall, New Jersey, ISBN:0-13-751215-5;1999.

42. Holzbecher E. Environmental modeling using MATLAB. Springer Berlin Heidelberg New, ISBN: 978-3-540-72936-5;2007

43. Hussain Z, Daosheng L, Xi L, Jiangxiong K. Defluoridation by a Mg-Al-La triple metal hydrous oxide: synthesis, sorption, characterization and emphasis on the neutral $\mathrm{pH}$ of treated water. RSC Adv. 2015;5:43906-43916.

44. Ramdani A, Taleb S, Benghalem A, Ghaffour NRemoval of excess fluoride ions from Saharan brackish water by adsorption on natural materials. Desalination 2010;250:408-413.

45. Habuda-Stanić M, Ravančić ME, Flanagan A. A review on adsorption of fluoride from aqueous solution. Materials 2014;7:6317-6366.

46. Valko M, Leibfritz D, Moncol J, Cronin MTD, Mazur M, Telser J. Free radicals and antioxidants in normal physiological functions and human disease. The Int. J. Biochem. Cell Biol. 2007;39:44-84.

47. Chassapis K, Roulia M, Vrettou E, Fili D, Zervaki M. Biofunctional characteristics of lignite fly ash modified by humates: A new soil conditioner. Bioinorg. Chem. Appl. 2010; 457964:1-8.

48. Andrson MP, Woessner WW. Applied groundwater modeling: simulation of flow and advective transport. 2nd Edition, Academic Press; 1992.

49. Abe I, Iwasaki S, Tokimoto T, Kawasaki N, Nakamura T, Tanada S. Adsorption of fluoride ions onto carbonaceous materials. J. Colloid. Interface Sci. 2004;275:35-39.

50. Sujana MG, Pradhan HK, Anand S. Studies on sorption of some geomaterials for fluoride removal from aqueous solutions. $J$. Hazard. Mater. 2009:161:120-125. 